\author{
Military Technical College \\ Kobry El-Kobbah, \\ Cairo, Egypt.
}

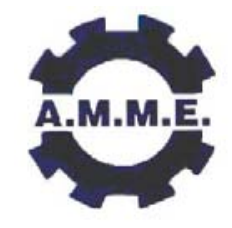

\title{
INTERLAMINAR FRACTURE TOUGHNESS OF MULTI-LAYER WOVEN SILK FIBRE/POLYESTER COMPOSITES
}

\author{
ZULKIFLI ${ }^{*}$ R., UCHENNA ${ }^{* *}$ A.U., PEI ${ }^{* *}$ K.S. and AZHARI ${ }^{* \star *}$ C.H.
}

\begin{abstract}
The effect of the number of layers of woven silk fibre on the interlaminar fracture toughness of silk/polyester composites which is a measure of the resistance of the material to delamination crack propagation has been studied. The multi-layer woven silk fibre/polyester composites were produced by compression moulding technique with increasing layers of silk of between 8 and 14 layers in thermoset polyester. The composite panels have been tested for mode I interlaminar fracture using double cantilever beam specimens (DCB) testing method. It was found that the interlaminar fracture toughness, $G_{I C}$ of the composite increases as the number of silk fibre layers increases. Stable crack propagation is observed during the tests and the crack propagation areas showed all the fibres were bare with no matrix covering them as were seen at 100x and 500x magnification using SEM. Failure occurred at the fibrematrix interface with no fibre bridging observed between the two fracture surfaces. The smooth clean surface of the silk fibres is the result of poor interfacial debonding and the increases in interlaminar fracture toughness is also due to improve strength of the composites panel.
\end{abstract}

\section{KEY WORDS}

Interlaminar fracture toughness, composite materials, silk fibre, polyester and scanning electron microscopy.

\footnotetext{
* Senior Lecturer, ${ }^{* *}$ Graduate student, ${ }^{* * *}$ Undergraduate student, ${ }^{* * *}$ Professor, Department of Mechanical \& Materials Engineering, Universiti Kebangsaan Malaysia.
} 


\section{INTRODUCTION}

Composite materials are well known as an excellent structural materials. Composite materials consist of two or more materials (i.e. fiber and matrix) combined to give superior performance compared to the properties of the individual components [1-3]. Woven silk fiber reinforced polyester has been used as structural materials for solar car body due to their cost and weight advantages compared to carbon fiber/epoxy. Manufacturing of structural materials made from woven silk fiber/polyester composites calls for an improved technique to improve the interlaminar fracture toughness of the composites. The interphase between fibers and polymers has a strong impact on composite properties [4-5]. For woven silk fiber/polyester composites, the interphase properties are determined by a surface coating, the so-called sizing, which is applied to the silk fibers during manufacture. Another method to increase the interlaminar fracture toughness is by increasing the number of layer of silk fiber so that increased stiffness will also increases interlaminar fracture toughness of the composites.

Delamination is the most predominant and life limiting failure mechanism in composite materials, hence limiting the use of composites for structural applications. Laminated composite structures subjected to static, impact and/or cyclic loads may suffer significant inter-laminar damage as a result of insufficient interlaminar toughness. There are three basic modes of deformation by which a load can operate on a crack. Each will effect a different crack surface displacement. In mode I, or the opening mode, displacements of crack surfaces are perpendicular to the crack plane and open the crack. In mode II, or the shearing mode, the surfaces slide over each other in the direction parallel to the crack. Lastly in mode III, or the tearing mode, the surfaces slide over each other in the out-of-plane direction. Delamination propagation is caused not only by interlaminar normal (mode-I) and in-plane shear (mode-II) stress fields but also the inter-laminar out-of-plane shear (mode-III) stress field [6-8]. Delamination can be considered using fracture mechanics approach with the critical strain energy release rate as a criterion.

All three individual and/or mixed interlaminar toughnesses must be measured in order to characterize fully the interlaminar fracture properties of composite laminates. The mode-I fracture toughness of laminated composites is successfully measured by double cantilever beam (DCB) test method [9-13]. The mode-Il fracture toughness is also obtained by the comparatively simple end notched flexure (ENF) test method $[9,13,14]$. Mixed in-plane shear and normal (mode-I and II) fracture tests can be also conducted by cracked lap shear (CLS) tests $[9,10]$. Experimental techniques for measuring modeIII toughness have been proposed by several workers [15,16], however, they are not as practical as those proposed for measuring the mode-I and -II toughness. An interesting method for measuring Mode III interlaminar toughness, called the edge crack torsion (ECT) test, has been proposed by Lee [17]. The distribution of the energy release rate along the crack front and necessary condition to obtain uniform energy release rate etc. are not well discussed. To utilize the method, more a rigorous equation for estimating the $G_{\| I}$ value should be given and necessary conditions must be well discussed. However, the ECT test method is still attractive for measuring the mode-III fracture toughness, because the experiments are simple and easy to conduct, like the DCB and ENF test methods. 
The aim of the project is to investigate how the effect of using different layers of woven silk fibers will influence the mode I interlaminar fracture properties of the woven silk fiber/polyester composites.

\section{EXPERIMENTAL METHODS \& MATERIALS}

The material used was a silk fiber reinforced polyester composite with four different number of silk fiber layers. The panels were prepared by a compression moulding technique. In order to initiate delamination, a treated release film of thickness $13 \mu \mathrm{m}$ was placed at laminate mid-thickness during moulding. The thickness of the film was sufficiently thin so as to minimize disturbance of the composite during manufacture. The length of the starter film from the loading line was chosen to be $50 \mathrm{~mm}$ so that the influence of the hinges can be neglected.

All specimens were nominally of $20 \mathrm{~mm}$ width and $4 \mathrm{~mm}$ thickness. The specimens had piano hinges blocks bonded to the starter defect end to permit load introduction. The hinge and the specimen were lightly abraded using a sandpaper since the load required to delaminate the specimens in these tests are quite low. Bonding of the loading tabs was done immediately after surface preparation. The bonding adhesive used was a room temperature cure epoxy adhesive. In order to minimize errors in the applied moment arm, the distance from the hinge pin to the center line of the specimen arm did not exceed $10 \mathrm{~mm}$. The number of silk layers used for the composites are 8, 10, 12 and 14 layers. Figure 1 shows the cross-section of the laminated composites.

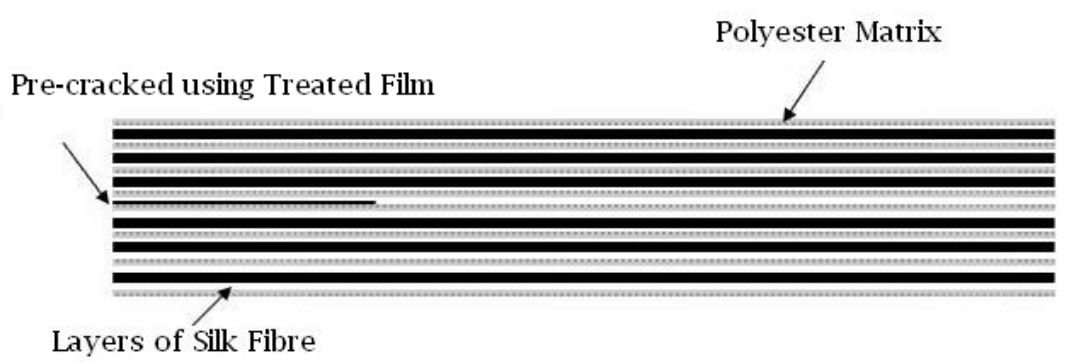

Fig. 1. Cross-section of the laminated silk fiber/polyester composites

The tests were conducted according to the European Structural Integrity Society (ESIS) Protocol for mode I interlaminar fracture testing of composites [18]. The detailed geometry of the Double Cantilever Beam specimen is shown in Figure 2. All tests were conducted on an Instron Universal Testing machine. A $5 \mathrm{kN}$ load cell was used since the maximum load never exceeded $4 \mathrm{kN}$. The specimen was loaded at a crosshead rate of $5 \mathrm{~mm} /$ minute. At this loading rate, crack propagation can be followed visually and recorded reasonably well. Load and displacement data were recorded continuously by a personal computer at a rate of 10 points per second.

To monitor the position of the crack tip, both sides of the specimen were coated with the white correction fluid to enhance the visibility of the propagating crack. At intervals of $5 \mathrm{~mm}$, the delamination length measured visually on a scale marked using the 
correction fluid, was noted together with the corresponding load and displacements. The point on the load-displacement plot at which the crack first propagated from the insert was also recorded. When crack has propagated at least $60 \mathrm{~mm}$ from the starter film, the test was stopped and the specimen was then completely unloaded.

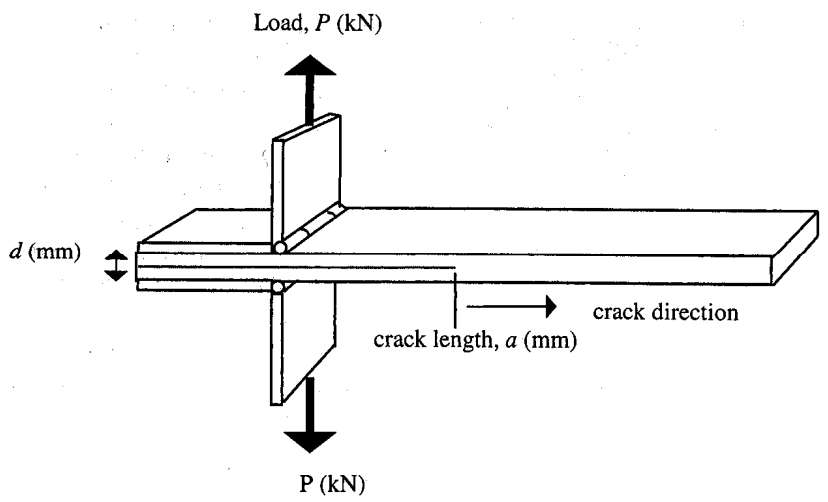

Fig. 2. Geometry of the double cantilever beam specimen

The fracture surfaces of the specimen was then analyzed on both side of the ply using the scanning electron microscope. The micrograph of the fracture surface of the specimens are very important in giving information on the fiber-matrix failure mechanism. Figure 3 and 4 show the Scanning Electron Microscopy images of the silk fiber at $100 \mathrm{X}$ and $500 \mathrm{X}$. The average value of the silk fiber was determined to be around $12 \mu \mathrm{m}$.

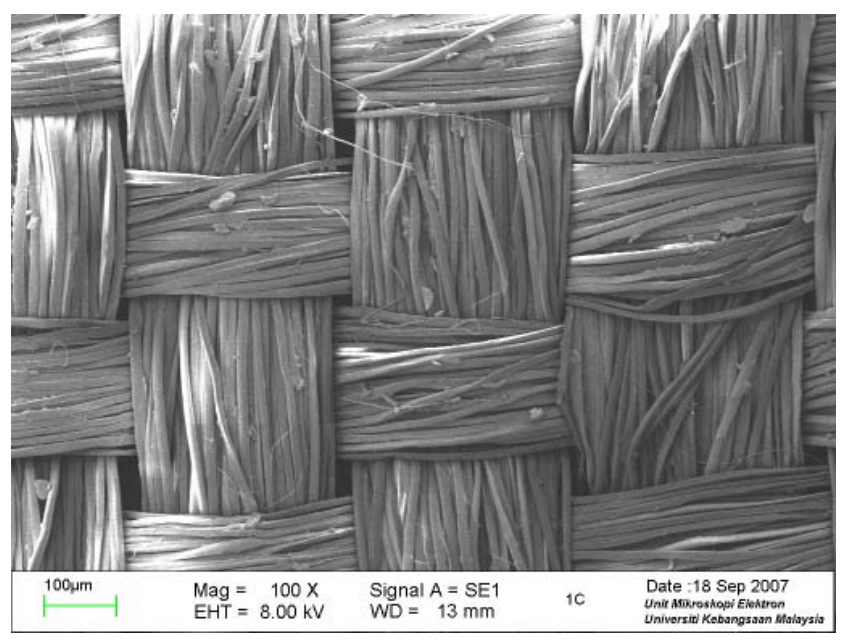

Fig. 3. Scanning Electron Microscopy image of the silk fibre at $100 x$ 


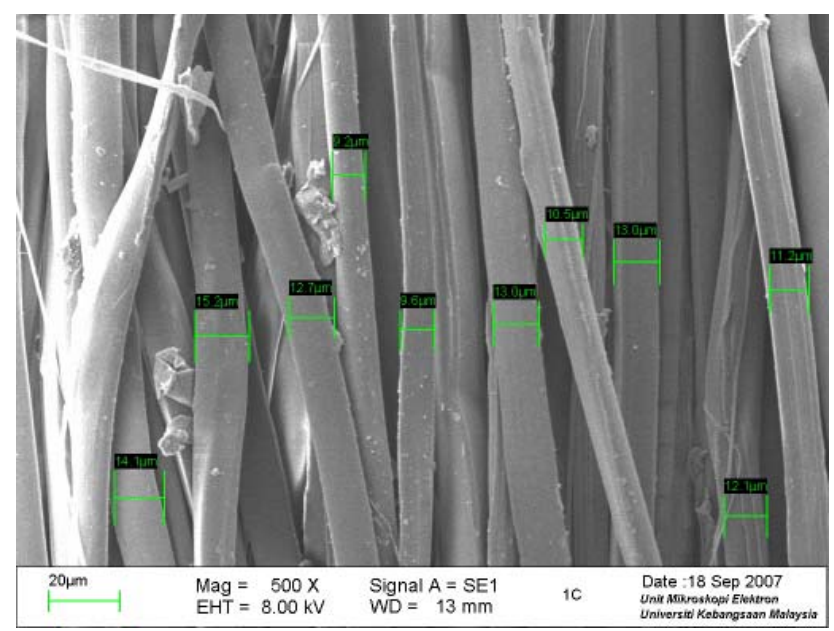

Fig. 4. Scanning Electron Microscopy image of the silk fibre at 500x

\section{DATA ANALYSIS}

The propagation values of the interlaminar fracture toughness were determined using the corrected beam theory. The simple beam theory expression for the compliance of a perfectly built-in DCB specimen is as follows;

$$
G_{I C}=\frac{3 P d}{2 B a}
$$

where $P$ is the load, $\mathrm{d}$ is the displacement, $B$ is the specimen width and $a$ is the crack length.

The formula above will underestimate the compliance because the beam is not perfectly built-in, hence the beam must be treated as containing a slightly longer crack, $a+D$, and $D$ may be found experimentally by plotting the cube root of compliance, $C^{1 / 3}$, as a function of crack length as shown in Figure 6 for 10 layers silk fibre. $G_{I C}$ is then given by;

$$
G_{I C}=\frac{3 P d}{2 B(a+D)}
$$

where $P$ is the load, $d$ is the displacement, $B$ is the specimen width and $a$ is the crack length and $D$ is the value of intersection between the plot line and the $x$-axis.

\section{RESULTS AND DISCUSSIONS}

The average values of $G_{I C}$ determined for a different layers of silk is shown in Table 1. Five specimens were tested for every number of silk fiber layers studied. Stable crack growth was observed over all the specimens and is shown on the graph of load $(P)$ 
against displacement $(d)$ in figure 5 for 10 layers woven silk fabric. Increasing the number of silk layers were found to increase the stiffness and interlaminar fracture toughness in woven silk fibre/polyester composites. The results show that the propagation values away from the point of crack initiation were very much higher than that of initiation values. The toughness values at initiation from the insert are required because in most woven double cantilever beam specimens, fibre bridging occurs as the delamination progress along the length of the beam and increases the energy required to propagate the delamination further. The initiation values of $G_{I C}$ are also of great interest since they are the lowest values and therefore offer the most conservative values for the design considerations [8].

Fiber bridging resulted in a significant increase in $G_{I C}$ values [6-7]. Stable delamination are observed in the load-displacement curve for all composites specimens. Instead of the load decreasing rapidly from the onset of delamination growth, the delamination grew slowly and the load did not decrease. The cause for the stable delamination growth is that the increase in interlaminar fracture toughness cause by fiber layers occurs at a greater rate than the decrease of the strain energy release rate. However, values of $G_{I C}$ obtained from the delamination growth from the insert is unaffected by fiber layer. The characteristics of fracture development after fiber-matrix separation (debonding along the fiber / matrix interface) gives further indication of the interface strength.

Table 1. Initiation and propagation interlaminar fracture toughness, $G_{I C}$ for all composition of silk/polyester

\begin{tabular}{ccc}
\hline Material & $\begin{array}{c}\mathbf{G}_{\mathbf{I C}} \text { (Initiation) } \\
\mathbf{k J / \mathbf { m } ^ { 2 }}\end{array}$ & $\begin{array}{c}\mathbf{G}_{\mathbf{I C}} \text { (Propagation) } \\
\mathbf{k J / \mathbf { m } ^ { 2 }}\end{array}$ \\
\hline 8 plies silk/polyester & 0.436 & 0.847 \\
\hline 10 plies silk/polyester & 1.030 & 1.530 \\
\hline 12 plies silk/polyester & 1.244 & 1.638 \\
\hline 14 plies silk/polyester & 1.687 & 1.872 \\
\hline
\end{tabular}

Results obtained shows very little scatter in the experimental data. Davies et al. [18] conducted a series of mode I double cantilever beam tests on IM6/PEEK composites. Their results indicated that the mode I propagation values of $G_{I C}$ are dependent on specimen thickness. This thickness effect is related to the contribution of multiple cracking and fiber bridging which results in higher values being obtained on thicker specimens.

Figure 5 and 6 show the graph of load against displacement and the graph of $C^{1 / 3}$ versus crack length (a) for corrected beam theory for 10 layer woven silk fiber/polyester composites. All the sample specimens show the same pattern of graph of load against displacement as shown in figure 5. From the values of maximum load and the load at the point of non-linearity, the interlaminar fracture toughness, $G_{I C}$ at recorded length was calculated. The interlaminar fracture tests on the DCB specimens resulted in a linear loading curve up to initiation from the insert. The values of $G_{I C}$ obtained in the current experiments show very little scatter suggests that the test set-up is reliable. 


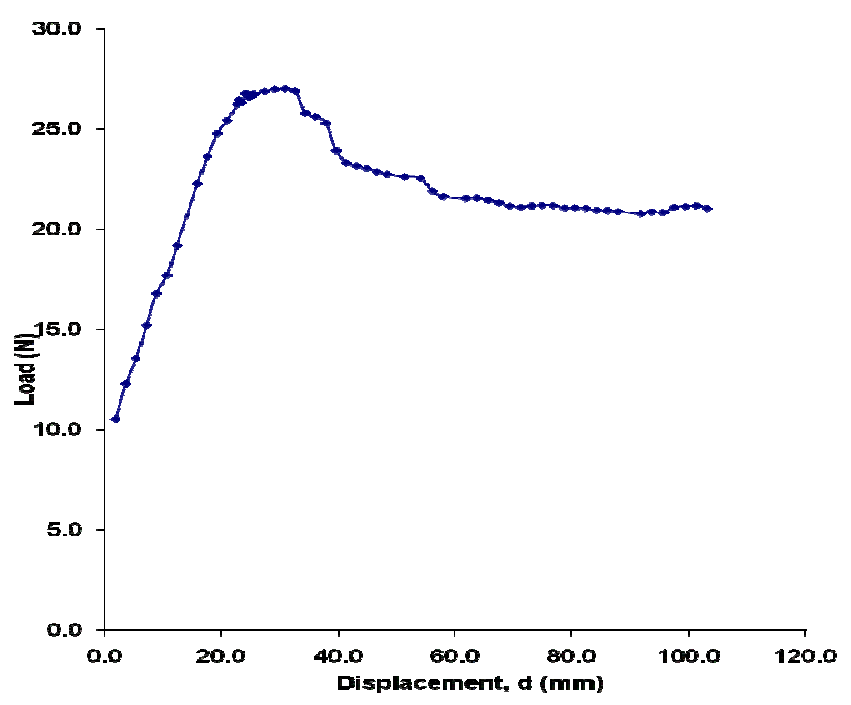

Fig. 5. Graph of load $(P)$ against displacement $(d)$ for 10 layers silk fibre

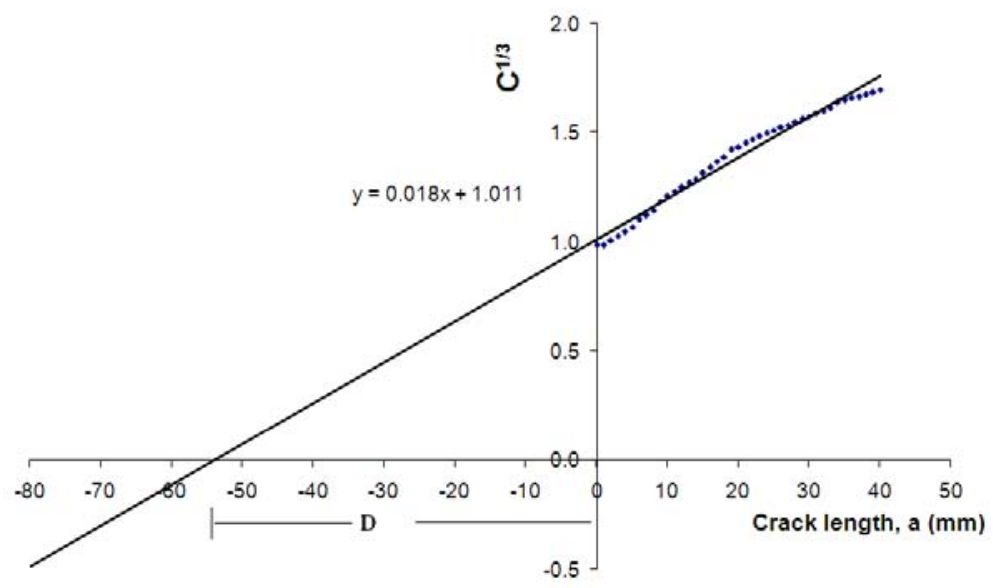

Fig. 6. Graph of $C^{1 / 3}$ versus crack length (a) for corrected beam theory

\section{CONCLUSION}

This experiment shows that increase in the number of layers of fiber is influencing the interlaminar fracture toughness of woven silk fiber reinforced polyester composites for the specimens with the same thickness of $4 \mathrm{~mm}$. The measured value is attributed to the toughness of the matrix over a reduced section caused by the presence of the nonadhering fibers. The results give the indication of the effect of the layers because the thickness of all the specimens are the same. In order to increase the interlaminar fracture toughness of composites, the number of layers of silk fiber need to be increased up to the maximum volume fraction of silk fiber. However, for the manufacture of woven silk fiber/polyester for solar car applications, due consideration must be given to the high costs of silk fiber if more layers of silk are required for improved interlaminar fracture toughness properties of these composites. 


\section{REFERENCES}

[1] Baral, N., Davies, P., Baley, C. and Bigourdan, B., "Delamination behaviour of very high modulus carbon/epoxy marine composites", Composites Science and Technology, Vol. 68(3-4), pp 995-1007, (2008).

[2] Mathews, M.J. and Swanson, S.R., "Characterization of the interlaminar fracture toughness of a laminated carbon/epoxy composite", Composites Science and Technology, Vol. 67(7-8), pp 1489-1498, (2007).

[3] Palley, A., "A fracture mechanics approach to interlaminar failure of unidirectional reinforced composites", Journal of Reinforced Plastics and Composites, Vol. 9, pp 174-181, (1990).

[4] Wetherhold, R.C., Corjon, M. and Das, P.K., "Multi-scale considerations for interface engineering to improve fracture toughness of ductile fiber/thermoset matrix composites", Composites Science and Technology, Vol. 67(11-12), pp 2428-2437, (2007).

[5] Thomason, J.L. and Schoolenberg, G.E., "An investigation of glass fibre/polypropylene interface and its effect on composite properties", Composites, Vol. 25, no. 3, pp 197-203, (1994).

[6] Huang, X.N. and Hull, D., "Effects of fibre bridging on $\mathrm{G}_{\mathrm{IC}}$ of a unidirectional glass/epoxy composite", Composites Science and Technology, Vol. 35, pp. 283-299, (1989).

[7] Martin, R.H., "Mode I and mode II static and fatigue delamination characterisation of woven composites", Proc. 3rd Int. Con. on Deformation and Fracture of Composites, pp 297-306, (1995).

[8] De Morais, A.B. and De Moura, M.F.S.F., "Evaluation of initiation criteria used in interlaminar fracture tests", Engineering Fracture Mechanics, Vol. 73(16), pp 2264-2276, (2006).

[9] Carlsson, L.A. and Pipes, R.B., Experimental characterization of advanced composite materials. Englewood Cliffs (NJ): Prentice-Hall, (1987)

[10] Wilkins, J.R., Eisenmann, R.A., Camin, R.A., Margolis, W.S. and Benson, R.A., "Characterizing delamination growth in graphite-epoxy, damage in composite materials", ASTM STP, pp 775-168, (1980).

[11] Bascom, W.D., Bitner, R.J., Moulton, R.J. and Siebert, A.R., "The interlaminar fracture of organic-matrix woven reinforced composites", Composites, pp 11-9, (1980).

[12] Wang, S.S., Suemasu, H. and Zahlan, N., "Interrlaminar fracture of random short-fiber SMC composite", Journal of Composite Materials, No.18, pp 57494, (1984).

[13] Suemasu, H., Hososda, H. and Nara K. "An experimental study of interlaminar toughness of satin woven fabric composite", Journal of Japan Society for Composite Materials, Vol.13(5), pp 225-32, (1987).

[14] Carlsson, L.A., Gillespie, J.W. and Pipes, R.B., "On the analysis and design of end notched flexure (ENF) specimen for measuring mode II fracture toughness", Composite Science and Technology, pp 20-594, (1986).

[15] Becht, G. and Gillespie, J.W., "Design and analysis of crack rail shear specimen for mode III interlaminar fracture", Composite Science and Technology, pp 31-143, (1988).

[16] Donaldson, S.L., "Mode III interlaminar fracture characterization of composite materials", Composite Science and Technology, pp 32-225, (1988).

[17] Lee, S.M., "An edge crack torsion method for mode III delamination fracture 
toughness", Journal of Composites Technology and Research (JCTRER), [18] Vol.15(3), pp 193-201, (1993).

Davies, P., "Protocol for interlaminar fracture toughness testing of composites", European Structural Integrity Society (ESIS), Polymer and Composite Task Group, IFREMER, Best, France. 